This is a post-peer-review, pre-copyedit version of an article published in Current Psychology. The final authenticated version is available online at https://doi.org/10.1007/s12144-020-00740-1

\title{
The bandwidth dilemma applied to trait emotional intelligence: Comparing the contribution of the emotional intelligence factor with its facets for predicting global job satisfaction
}

Building upon the relevance of emotional intelligence (EI) in influencing key attitudes at work, the current study aimed to compare the contribution of the trait-EI factor with its specific facets for predicting overall job satisfaction. Relying on a concurrent design, results from a sample of 228 software engineers from a multi-national firm showed that trait-EI global factor remained a significant and non-redundant predictor of this attitudinal criterion, even when the big five are also taken into consideration. Results also revealed that corresponding facets of self-emotions appraisal, other-emotions appraisal, use of emotion, and regulation of emotion, when residualized (i.e., their factor variance is partialed out), do not outperform the contribution of the higher-order trait-EI factor and the big five in the prediction of overall job satisfaction. Theoretical and practical implications of these results are discussed.

Keywords: emotional intelligence, trait-EI, job satisfaction, bandwidth dilemma. 


\section{Introduction}

Emotional intelligence (EI) has raised a substantial amount of interest in the scope of research about the role of individual differences in shaping behaviors and attitudes at work (Lievens \& Chan, 2017; Sackett, Lievens, Van Iddekinge, \& Kuncel, 2017). Since its inception in the literature, commonly credited to Salovey and Mayer (1990), as the ability to deal effectively with emotions and emotional knowledge, EI has received great acceptance from business management practitioners as one of the most promising predictors of job performance (Goleman, 1998).

In contrast, early scientific research developments caused vivid debate regarding the theoretical and applied value of EI for understanding and predicting human behavior in the workplace. This debate was fueled by various early concerns regarding its lack of theoretical clarity, related measurement issues, and potential conceptual redundancy with wellestablished performance predictors, such as cognitive ability and personality (Locke, 2005; Matthews, Zeidner, \& Roberts, 2002; Van Rooy, Whitman, Viswesvaran, 2010).

Notwithstanding, more recent meta-analyses have shown that EI constitutes a valid predictor of individual job performance (Joseph \& Newman, 2010; O’Boyle, Humphrey, Pollack, Hawver, \& Story, 2010) and of some of its key behavioral dimensions, like organizational citizenship behaviors and counterproductivity (e.g., Miao, Humphrey, \& Qian, 2017a). Concomitantly, primary and meta-analytic research has also revealed that EI measures may be among the most promising individual predictors of job satisfaction, given their sizeable links with this key job attitude (Miao, Humphrey, \& Qian, 2017b).

In spite of these developments, previous research has been predominantly focused on the criterion-related validity of the EI global factor, leaving largely unexplored the question of whether specific EI dimensions or facets might vary in prominence, or even outperform the factor, when predicting critical work-related criteria, like job performance and job satisfaction 
(Carmeli \& Josnam, 2006; Greenidge, Devonish, \& Alleyne, 2014). At its core, addressing such a research question implies the examination of what is commonly known as the bandwidth-dilemma paradox or the bandwidth-fidelity dilemma. Despite remaining behind some of the most stimulating debates in recent research about the validity of key individual differences constructs, this dilemma has a long and vivid tradition in the literature (Judge \& Kammeyer-Mueller, 2012; Steel, Uggerslev, Bosco, \& Uggerslev, 2018). Cronbach and Gleser (1957) were the first researchers to address this matter and to discuss its major implications for psychological testing and validity. According to these authors, there is an inherent compromise, or trade-off, between the bandwidth of a given measure and its fidelity or precision. When applying the bandwidth-fidelity dilemma to a given predictor-criterion relationship, the authors reasoned that whereas broad predictor measures can attain moderate validity, maximum validity demands a closer degree of fidelity between the predictor and the criterion, implying that a narrow predictor will capture the particularities of a specific criterion more effectively.

Since then, the bandwidth-fidelity dilemma assumptions regarding the extent to which higher-order (broader) versus lower-order (narrower) predictor constructs yield the best prediction of work-related criteria, especially of job performance, have been intensely studied and debated in the frame of well-established individual's predictors, such as cognitive ability and personality factors (e.g., Ree, Earles, \& Teatchout, 1994; Ones \& Viswesvaran, 1996; and Salgado, 2017, for a review). Nonetheless, to the best of our knowledge, the bandwidthfidelity dilemma remains unexplored as applied to EI.

Still, such an examination raises important applied implications for EI assessment and related decision-making purposes, irrespective of the specific EI approach followed, since it allows a diagnosis of whether to use the global EI-factor or, alternatively, to rely on the level of EI specific facets to grant greater prediction of a given criterion. Furthermore, scrutinizing 
this question also raises significant theoretical implications, as it allows a diagnosis of whether to consider specific conceptual elements encompassed in EI facets along with the global factor for efforts towards developing theory regarding the determinants of critical organizational behavior variables, like work performance and job satisfaction.

A comprehensive examination of this matter, when adopting job satisfaction criteria, requires an analysis of which level of EI predictor breadth (i.e., EI broad factor or its narrow facets) warrants a stronger prediction of a broader criterion of global job satisfaction, but also scrutiny of which breadth of EI measurement yields higher validity in predicting narrower job satisfaction facets. As one of the first attempts to address the bandwidth-fidelity dilemma in the scope of EI, the current study is focused on the former, by comparing the contribution of a global EI-factor and its specific facets for predicting overall job satisfaction.

This study has adopted this criterion not solely due to the underdevelopment of research on the validity and mostly on the incremental validity of EI for its prediction, especially when compared with the large number of studies using performance criteria, but also given the prominence of job satisfaction for both the worker and the organization (Judge \& Kammeyer-Mueller, 2011). Besides its intrinsic worth for workers, as a key dimension of life satisfaction which in turn is part of individual subjective well-being (Judge \& Klinger, 2008; Steel et al., 2018), this job attitude is, likewise, paramount for organizations due to its positive influence on important outcomes such job performance (Bowling, Khazon, Meyer, \& Burrus, 2015; Judge, Thoresen, Bono, \& Patton, 2001; Riketta 2008).

Since EI research relies on multiple conceptualizations and non-equivalent measurement approaches (see Ashkanasy \& Daus, 2005, for the distinction between EI research streams) it is worth clarifying that this study follows a trait-EI conceptualization consistent with Mayer and Salovey's (1997) EI definition and related theoretical dimensions. More specifically, it adopts the four trait-EI facets proposed by Davies, Stankov and Roberts' 
(1998) literature review, further studied by Wong, Law and colleagues (e.g., Law, Wong, \& Song, 2004; Wong \& Law, 2002), including self-emotions appraisal, others-emotions appraisal, use of emotion and regulation of emotion. Unlike the ability-EI approach, which posits this construct as a set of cognitive abilities (i.e., branches, assessed through performance-based tests) for processing emotional knowledge and dealing with emotionrelated problems (Mayer \& Salovey, 1997), trait-EI conceives it as the individual perception (assessed through self-report) about one's own abilities to perceive, understand, regulate and use emotions to adapt to the environment and enhance well-being (Lievens \& Chan, 2017; Petrides, Mikolajczak, Mavroveli, Shanchez-Ruiz, Furnham, \& Pérez-González, 2016).

To allow a more accurate examination of the bandwidth-fidelity dilemma applied to EI-job satisfaction links, the contribution of the big five personality factors was also examined and controlled. In addition to their relationships with EI, especially for trait-EI, some of the big five represent meaningful predictors of job satisfaction (e.g., Bruk-Lee, Khoury, Nixon, Goh, \& Spector, 2009; Judge, Heller \& Mount, 2002; Steel et al., 2018). Nonetheless, according to our literature review, research accounting for the effects of personality factors when analyzing EI criterion-related validity for predicting job satisfaction remains very scarce.

\section{Bandwidth-fidelity dilemma applied to EI on the prediction of job satisfaction}

As posited by the dispositional approach (see Staw \& Cohen-Charash, 2005, for a review), individual dispositions effectively matter in the degree to which individuals experience job satisfaction, i.e. a pleasurable or positive emotional state as a consequence of the appraisal of their job experiences (Locke, 1976). Consistently, cumulative empirical reviews have uncovered meaningful correlates between personality dispositions, mapped 
within the big five taxonomy, and this core job attitude (Bruk-Lee et al., 2009; Judge et al., 2002; Steel et al., 2018).

Moreover, recent meta-analytic evidence also suggests that measures of global EI, including those drawing upon the trait-EI conceptualization, represent significant and generalized predictors of job satisfaction, due to its positive and meaningful links with job satisfaction across employee age, tenure and job levels (Miao, Humphrey, \& Qian, 2017b). Particularly for trait-EI, such findings suggest that individuals who appraise their effectiveness in perceiving, understanding and regulating emotions more favorably tend to experience improved levels of job satisfaction. Accordingly, high-EI individuals are posited to display positive moods more often and cope better with stressful and negative work events, mitigating their detrimental effects and adopting a more optimistic outlook when appraising their job experiences (Greenidge et al., 2014; Kaftesios \& Zampetakis, 2008).

As it stands for self-emotions appraisal, others-emotions appraisal, use of emotion and regulation of emotion respective trait-EI facets, despite the non-existence of meta-analytic estimates at this level, initial evidence from primary research, in addition to revealing a positive pattern of relationships of these facets with job satisfaction, also suggests that they might play distinct roles in enacting positive levels of individual satisfaction at work. Whereas regulation of emotion, i.e. the effectiveness of inducting positive states and modulating own and other's emotions, might affect job satisfaction through interpersonal mechanisms by enhancing social work interactions, the accurate appraisal of emotions (i.e., self-emotions appraisal and others-emotions appraisal facets) and the use of emotion to facilitate individual performance (i.e., use of emotion facet), might impact on job satisfaction via intrapersonal mechanisms, linked with improved performance levels (Greenidge et al., 2014; Kaftesios \& Zampetakis, 2008; Wong \& Law, 2002). 
Yet, while prior research has supported the positive effect of both EI global trait and respective facets on job satisfaction, less attention has been paid to the comparison of their specific contributions for the prediction of this work-related attitude, leaving the bandwidthfidelity dilemma practically unaddressed at this level.

In the discussion of the bandwidth-fidelity dilemma with respect to job attitudes, Hulin (1991) has contended that maximum empirical prediction demands matching the level of specificity of predictor with the criterion, implying that broad attitudes will be better predicted by global predictors. Building upon these developments, Judge and KammeyerMueller (2012) further recommended researchers to rely on broad psychological constructs when the intent is to develop broad theoretical generalizations, while narrow psychological constructs will be more suited for theoretical development purposes which are contextspecific.

Thus, transposing these recommendations for the bandwidth-fidelity dilemma regarding the predictive value of EI measures towards job satisfaction, it seems plausible to expect that EI facets will not outperform the trait-EI global factor when the aim is to predict a broad attitudinal criterion, i.e. overall job satisfaction, as well as explaining how trait-EI might impact on job satisfaction across jobs. Therefore, we hypothesize that trait-EI facets of will show no incremental validity over the EI global factor for predicting overall job satisfaction.

To test this hypothesis, we took into account two relevant and interconnected contributions from previous research about the bandwidth-fidelity dilemma applied to other dispositional predictors, namely the big five. Even though their full discussion is beyond the scope of this paper, a brief mention is merited due to their important implications for related research. One such contribution stems from Judge and Kammeyer-Mueller's (2012) recommendation of using a hierarchical representation of the predictor when feasible. 
According to these authors, relying upon this representation warrants a more integrative approach when examining the bandwidth-fidelity dilemma, since it allows the estimation and comparison of criteria-related validity of both the broad (second-order) reflective factor and of its (first-order) dimensions or facets. Adopting such models when viable, in addition to better capturing the completeness and complexity of the predictor, also leave the possibility open for theoretical and empirical enquiry that narrower facets might possess specific variance that could offer increased validity for predicting criteria (Judge \& KammeyerMueller, 2012). This possibility is viable for trait-EI since previous evidence regarding some trait-EI measures, i.e. those consistent with Mayer and Salovey's (1997) EI definition, suggest the feasibility of such a hierarchical representation of respective trait-EI constructs (Kaftesios \& Zampetakis, 2008; Law at al., 2004; Iliceto \& Fino, 2017).

However, Judge and Kammeyer-Mueller (2012) have also highlighted that, as the "general factor is, by design, often highly correlated with the dimensions themselves for hierarchical constructs, this makes it challenging to isolate unique variance" (p. 169). Indeed, this is also the case for trait-EI, which calls into consideration an inter-related contribution made by Salgado, Moscoso, Sanchez, Alonso, Choragwicka, and Berges (2015) in the scope of the bandwidth-fidelity dilemma applied to links between big five and performance. According to these authors, such isolation of common variance (factor variance) from specific variance (facet variance) when addressing the bandwidth-fidelity dilemma is critical in accurately examining whether the validity yielded by the respective facets is due to the common factor variance that they encompass, rather than by its specific and idiosyncratic variance.

These authors further highlighted that this question was not fully addressed in previous research on the bandwidth-fidelity dilemma, entailing an important limitation that can help to explain the mixed findings obtained for personality-performance links, since some 
research supports the superiority of personality facets to predict narrow and broad performance criteria (e.g., Ashton, Paunonen, \& Lee 2014; Judge, Rodell, Klinger, Simon, \& Crawford, 2013), whereas other studies indicate that global factors hold stronger predictive power (e.g., Ones \& Viswesvaran 1996; Salgado, Moscoso, \& Berges, 2013; Salgado et al., 2015). By developing a method to perform such separation and derive residualized facets (i.e., partialing out their common factor variance) Salgado et al. (2015) have shown that personality facets do not show incremental validity over the big five global factors for predicting academic and job performance, regardless of the breadth of these criteria.

\section{Method}

\section{Participants and procedure}

This study was conducted with a sample of engineers, pertaining to a single job of software project engineering from a multinational information technology firm. Organized in small semi-autonomous teams, their main duties included software coding, testing quality assurance and project management. Following a concurrent design, all 305 software engineers were invited to complete an on-line survey, during regular working hours, including the measures of trait-EI and job satisfaction. The main research goals were explained and their informed consent was requested, warranting confidentiality and use of their answers for research purposes only. Complete data was obtained for 228 incumbents, corresponding to a response rate of approximately $75 \%$. The majority of the participants were male (94\%), aged 31.21 years on average $(S D=5.08)$ and had a mean of 3.79 years $(S D=2.42)$ of organizational tenure.

\section{Measures}

Emotional intelligence was measured through the Wong and Law self-report Emotional Intelligence Scale (WLEIS, Wong \& Law, 2002), especially designed for EI assessment in the 
workplace. Composed by 16 items, this scale evaluates the four EI dimensions formerly identified by Davies et al. (1998) including self-emotions appraisal, other's emotions appraisal, use of emotion and regulation of emotion. Each dimension is assessed with four items including "I have good understanding of my own emotions" for self-emotions appraisal; "I am a good observer of others' emotions" for other's emotions appraisal; "I always tell myself I am a competent person" for use of emotion and "I am quite capable of controlling my own emotions" for regulation of emotion. All items were provided with a 5point Likert response scale, ranging from 1 (strongly disagree) to 5 (strongly agree).

The total score on the scale is purported to represent a meaningful higher-order EI global factor, reflective of these four subdimensions. Prior research has provided evidence supporting this hierarchical representation of trait-EI as measured by the WLEIS (Iliceto \& Fino, 2017; Kaftesios \& Zampetakis, 2008; Law at al., 2004). Consistently, results from confirmatory factor analyses with the current sample revealed that this second-order (hierarchical) model yields a reasonably good fit level to the data $\left(\chi^{2}[100, N=228]=177.31\right.$, $p<.001 ; \mathrm{CFI}=.947 ; \mathrm{RMSEA}=.058 ; \mathrm{SRMR}=.059)$. Cronbach's alphas were .82 for global EI, .83 for self-emotions appraisal, .79 for other's emotions appraisal, .72 for use of emotion and .85 for regulation of emotion.

Job satisfaction was measured using the 5-item version from Brayfield and Rothe's (1951) scale, commonly used in research related to overall job satisfaction. An example item is "I feel fairly satisfied with my present job". Responses were obtained using a 5-point Likert scale where 1 = strongly disagree and $5=$ strongly agree. Previous research has supported the appropriateness of its psychometric characteristics (see Judge \& Klinger, 2008, for a review). Cronbach's alpha was .79.

Control variables. To control for the big five personality factors, Saucier's 40-item Mini-Markers (Saucier, 1994) was used. Each employee in our sample rated how accurately 
each item described himself using a 5-point Likert scale, ranging from 1 (extremely inaccurate) to 5 (extremely accurate). Cronbach's alphas were .88 for emotional stability, .74 for openness to experience, .77 for extraversion, .80 for conscientiousness, and .68 for agreeableness.

\section{Analytic strategy}

As previously highlighted, in order to test the bandwidth-fidelity dilemma applied to EI more accurately, respective facets should be residualized, i.e. factor variance (common variance) must be separated from facet variance (specific variance). To perform such residualization we followed the multi-step procedure adopted by Salgado and colleagues in their research about the bandwidth-fidelity dilemma on the links between personality and job performance (i.e., Salgado et al., 2013; Salgado et al., 2015), consisting of using hierarchical factor analysis followed by a Schmid-Leiman (1957) transformation.

Accordingly, in the first step, a first-order factor analysis with oblique rotation was conducted on the WLEIS data. This step was implemented to estimate respective trait-EI four facet scores. The next step consisted of carrying out a second-order factor analysis using these facets' scores as indicators. This second step was conducted in order to provide an estimate of the trait-EI factor. As expected, this analysis uncovered a second-order factor corresponding to the higher-order trait-EI construct. Correspondent trait-EI factor scores were saved and used as the estimate of trait-EI factor in subsequent criteria-related and incremental validity analyses. In the third step, a set of regression analyses was used, entering each of the four first-order factors as the dependent variable and the second-order trait-EI factor as the independent variable. This step was required to separate the unique variance of facets from trait-EI factor variance. Specifically, the residualized scores obtained from these analyses 
contain only specific variance of the facets and were therefore used as estimates of trait-EI residualized facets in further validity analyses.

Lastly, to test the hypothesis under study, a set of hierarchical regression analyses was implemented to estimate the incremental validity of residualized facets over the global trait-EI factor score, controlling for the big five. Hence, after entering the big five, which emerged as independent predictors of overall job satisfaction, the trait-EI factor score was entered in the second step of the regression analysis. Residualized facets entered in the third step (altogether by creating a linear composite) to access whether their specific variance will account for a relevant increment of explained variance, over and beyond trait-EI higher-order factor, on job satisfaction.

\section{Results}

Table 1 displays the means, standard deviations and correlations between all variables under study. As shown, the big five factors of extraversion and agreeableness were positively related to job satisfaction in the present sample. As expected, global trait-EI also established a positive and significant link with this criterion. The obtained validity coefficient for job satisfaction, when corrected for measurement error $\left(r_{x y}=.31,95 \%\right.$ confidence interval: .13-.42), was close to analogous meta-analytic estimates reported by Miao et al. (2017b) for the corresponding relationship between self-reported EI and job satisfaction for non-managerial jobs $(\rho=.33, k=41, N=13,929)$ and for male-dominated samples $(\rho=.34, k=28, N=7,270)$. With respect to EI facets, all were positively correlated with job satisfaction, yet other's emotions appraisal and regulation of emotion corresponding relationships were of low magnitude, while for other's emotions appraisal the correspondent link was only marginally significant.

(Insert table 1 around here) 
Table 2 shows the criteria-related validity coefficients of trait-EI higher-order factor score and of the correspondent four residualized facets (i.e., SEAr, OEAr, UOEr and ROEr) estimated through the procedure previously described. As shown, when facets contained specific variance only (i.e., are completely independent from the trait-EI factor), their relationships are approximately zero with the criterion under analysis. The sign of some coefficients turns negative, depicting a very similar pattern of results to those reported by Salgado et al. (2013), when assessing the validity of the residualized facets of conscientiousness to predict task performance. The only exception occurs for use of emotion, which remains positively related with job satisfaction, but the corresponding validity coefficient was of weak magnitude.

(Insert table 2 around here)

The main results from hierarchical regression analyses carried out to test the hypothesis under study by assessing the incremental validity of residualized facets over the trait-EI factor are reported in Table 3. As can be observed, after considering the variance of job satisfaction accounted for by the big five which emerged as valid predictors, i.e. extraversion and agreeableness, the trait-EI factor further accounts for approximately $3 \%$ of variance of this criterion in this sample $\left(\Delta R^{2}=.025, p<.05\right)$. Thus, the estimated joint contribution of these personality factors and trait-EI in terms of explained job satisfaction variance rises to approximately $10 \%$ in the current sample.

Still, the respective variation in square multiple correlation after entering the residualized facets composite was very modest and only marginally significant $\left(\Delta R^{2}=.014, p\right.$ $<.10$ ), suggesting that they do not hold incremental validity to predict job satisfaction over the big five and the trait-EI factor. Results are practically the same when entering with UOEr, i.e. the single residualized facet significantly linked with job satisfaction, in the third step of 
the analysis (step 3b), rendering a small and non-significant increment in the amount of explained variance in job satisfaction $\left(\Delta R^{2}=.011, n s\right)^{1}$.

(Insert table 3 around here)

\section{Discussion}

By addressing the bandwidth-fidelity dilemma applied to the trait-EI factor and its four facets of self-emotions appraisal, others-emotions appraisal, use of emotion and regulation of emotion for the prediction of overall job satisfaction, the current study made some contributions to the literature. As highlighted above, while primary and meta-analytic research revealed that both global trait-EI and its facets are positively related to performance and job satisfaction (Miao et al., 2017b; O’Boyle et al., 2010; Greenidge et al., 2014), research is uninformative about the superiority of the factor or corresponding facets to predict these criteria.

Our findings contribute to improve the understanding about this matter by showing that the trait-EI factor constitutes a valid and meaningful predictor of overall job satisfaction and respective facets do not explain additional variance of this job-related attitude. Despite being positively related with this criterion, results show that when facets are residualized (i.e., when only their specific variance is taken into account) they do not hold criteria-related validity towards this criterion. The single exception concerns the use of emotion facet, yet even in this case it does not show incremental validity over the global trait-EI factor and the big five. Therefore, these findings are aligned with Hulin's (1991) perspective on the

\footnotetext{
${ }^{1}$ As recommended by Salgado et al. (2015), we also calculated the respective square population cross-validity coefficients $\left(R_{\mathrm{cv}}^{2}\right)$, using Browne's (1975) formula, since both the multiple square regression $\left(R^{2}\right)$ or the adjusted $R^{2}$ coefficients can be biased by the capitalization on chance that occurs in multiple regression (Yin \& Fan, 2001). Obtained estimates were $R^{2}{ }_{\mathrm{cv}}=.062$ for step $1, R_{\mathrm{cv}}^{2}=.080$ for step $2, R^{2}{ }_{\mathrm{cv}}=.087$ for step $3 \mathrm{a}$ and $R_{\mathrm{cv}}^{2}=.083$ for step $3 \mathrm{~b}$ of the respective hierarchical regression analyses. In spite of their lower magnitude, these estimates depicted a similar pattern of findings in terms of incremental validity.
} 
discussion of the bandwidth-fidelity dilemma for job attitudes according to which broad attitudes will be better predicted by global predictors. Furthermore, our results also contribute to the literature by revealing that this higher-order trait-EI entails an individual disposition that is non-redundant with the big five in the explanation of overall job satisfaction.

Altogether, these findings point to both theoretical and practical implications. From a conceptual viewpoint, they support the merits ascribed to the dispositional approach to job satisfaction (see Staw \& Cohen-Charash, 2005) and further suggest that trait-EI might stand among the dispositional antecedents of this core attitudinal criterion. Since results also support trait-EI non-redundancy with the big five for explaining job satisfaction, they also indicate that trait-EI encompasses conceptual elements that might not be entirely covered by this personality taxonomy. As noted by Hulin and Judge (2003), “job satisfaction includes multidimensional psychological responses to one's job, and that such responses have cognitive (evaluative), affective (or emotional), and behavioral components" (p. 394). Thereby, it is plausible to posit that trait-EI might play a specific and differential role in enacting positive affect processes which are beneficial for more favorable job satisfaction appraisals. By enhancing job satisfaction, global trait-EI might act as a driver of subsequent beneficial effects of this core attitude, linked with increased well-being and individual performance (Judge \& Kammeyer-Mueller, 2011). In fact, initial empirical evidence gives credit to these aspects by showing that trait-EI influences job satisfaction via affective processes (e.g., Kaftesios \& Zampetakis, 2008) and that trait-EI ultimately facilitates performance behaviors by enhancing job satisfaction (e.g., Greenidge et al., 2014).

From a practical perspective, our findings indicate that relying upon a high-order factor of trait-EI does not result in potential prediction losses when the criterion is overall job satisfaction, since specific facets do not hold specific and reliable variance, apart from EI global factor variance, which effectively matters when predicting this attitudinal criterion. As 
such, a measure of the individual's global perception of own competence in dealing effectively with emotions to better adapt to environment and enhance well-being seem to has more applied value than any specific self-assessment of trait-EI facets, i.e. own and others' emotions perception, use of emotion or emotion regulation when the purpose is to predict a broad criterion of job satisfaction. These results somewhat resemble the picture from metaanalytic research concerning the bandwidth-fidelity dilemma applied to effects of personality traits on job satisfaction (i.e., Steel et al., 2018) since personality facets only accounted for a minor increase in explained variance of overall job satisfaction when broad factors are also considered.

In spite of these contributions, this study has some limitations. In particular, it should be noted that our results only shed partial light on the bandwidth-fidelity dilemma applied to trait-EI job satisfaction links, since a single and broad criterion of job satisfaction was used. Future research should capitalize upon the feasibility of the hierarchical model for trait-EI and include both broad (i.e., overall satisfaction) and narrow job satisfaction (i.e., satisfaction facets) criteria to allow a more informative discussion of the bandwidth-fidelity dilemma. In particular, the use of satisfaction facets might capture important particularities of job satisfaction appraisals for which more specific trait-EI facets might impact differently and eventually stronger than the trait-EI global factor. For example, due to its instrumental role in improving the quality of social work interactions by inducting positive affect states and modulating own and others emotions, the facet of regulation of emotion might become more important than the trait-EI factor for predicting job satisfaction facets that mostly subsume interpersonal aspects of the job, like satisfaction with supervision and peers. This might represent a pertinent clue for future research since, as underlined by Ashton et al. (2014) in the scope of the debate on the bandwidth-fidelity dilemma in personality and performance, facet-level predictors might hold superior validity than factor-level scales, especially when 
there is "some strong conceptual link between a given facet-level scale and a criterion variable" (p. 24).

Another limitation stems from the reliance of our findings on a single job of software engineering from a multi-national company, pertaining to the information-technology industry, which constrains the generalizability of our findings. Furthermore, using a predominantly male sample constitutes an additional constraint to generalization of our results, especially given the previous empirical evidence indicating that "men did score lower on self-perceived EI, which suggests that they think of themselves as less confident in perceiving, understanding and regulating emotions than did women" (Fischer, Kret, \& Broekens, 2018, p. 14). Therefore, future studies with more gender-balanced samples, representing different jobs and industries, is certainly needed before more solid conclusions can be drawn.

In conclusion, the current study supports the criterion-related validity of trait-EI factor for overall job satisfaction and maps this construct as an individual disposition, non-redundant with the big five, that contributes to shaping this critical attitudinal response at work. It has also evidenced that trait-EI corresponding facets do not account for specific variance on this criterion beyond the high-order factor, recommending that global factor scores be employed when the purpose is to predict satisfaction at work.

\section{Compliance with Ethical Standards}

\section{Ethical Approval}

All procedures performed in studies involving human participants were in accordance with the ethical standards of the institutional and/or national research committee and with the 1964 Helsinki declaration and its later amendments or comparable ethical standards. Approval to conduct this study was obtained. 


\section{Informed Consent}

Informed consent was obtained from all individual participants included in the study.

\section{Conflict of interest}

On behalf of all authors, the corresponding author states that there is no conflict of interest.

\section{References}

Ashkanasy, N. M., \& Daus, C. S. (2005). Rumors of the death of emotional intelligence in organizational behavior are vastly exaggerated. Journal of Organizational Behavior, 26(4), 441-452.https://doi.org/10.1002/job.320

Ashton, M. C., Paunonen, S. V., \& Lee, K. (2014). On the validity of narrow and broad personality traits: A response to Salgado, Moscoso, and Berges (2013). Personality and Individual Differences, 56, 24-28.https://doi.org/10.1016/j.paid.2013.08.019

Bowling, N. A., Khazon, S., Meyer, R. D., \& Burrus, C. J. (2015). Situational strength as a moderator of the relationship between job satisfaction and job performance: A metaanalytic examination. Journal of Business and Psychology, 30(1), 89104.https://doi.org/10.1007/s10869-013-9340-7

Brayfield, A. H., \& Rothe, H. F. (1951). An index of job satisfaction. Journal of Applied Psychology, 35(5), 307-311.https://doi.org/10.1037/h0055617

Browne, M. W. (1975). Predictive validity of a linear regression equation. British Journal of Mathematical and Statistical Psychology, 28, 79-87.https://doi.org/10.1111/j.20448317.1975.tb00550.x 
Bruk-Lee, V., Khoury, H. A., Nixon, A. E., Goh, A., \& Spector, P. E. (2009). Replicating and extending past personality/job satisfaction meta-analyses. Human Performance, 22(2), 156-189.https://doi.org/10.1080/08959280902743709

Carmeli, A., \& Josman, Z. E. (2006). The relationship among emotional intelligence, task performance, and organizational citizenship behaviors. Human Performance, 19(4), 403419. https://doi.org/10.1207/s15327043hup1904_5

Cronbach, L. J., \& Gleser, C. G. (1957). Psychological tests and personnel decisions. Urbana: University of Illinois Press.

Davies, M., Stankov, L., \& Roberts, R. D. (1998). Emotional intelligence: In search of an elusive construct. Journal of Personality and Social Psychology, 75(4), 9891015.https://doi.org/10.1037/0022-3514.75.4.989

Fischer, A. H., Kret, M. E., \& Broekens, J. (2018). Gender differences in emotion perception and self-reported emotional intelligence: A test of the emotion sensitivity hypothesis. PLoS ONE, 13(1), e0190712.https://doi.org/10.1371/journal.pone.0190712

Goleman, D. (1998). What makes a leader? Harvard Business Review, 76, 93102.https://doi.org/10.1002/ lt1.40619981008

Greenidge, D., Devonish, D., \& Alleyne, P. (2014). The relationship between ability-based emotional intelligence and contextual performance and counterproductive work behaviors: A test of the mediating effects of job satisfaction. Human Performance, 27(3), 225-242.https://doi.org/10.1080/08959285.2014.913591

Hulin, C. L., \& Judge, T. A. (2003). Job attitudes. In W. C. Borman, D. R. Ilgen, \& R. J. Klimoski (Eds.), Handbook of psychology: Industrial and organizational psychology (pp. 255-276). Hoboken, NJ:Wiley. 
Hulin, C. L. (1991). Adaptation, persistence, and commitment in organizations. In M. D. Dunnette, \& L. M. Hough (Eds.), Handbook of industrial and organizational psychology ( $2^{\text {nd }}$ ed., Vol. 2, pp. 445-505). Palo Alto, CA: Consulting Psychologist Press.

Iliceto, P., \& Fino, E. (2017). The Italian version of the Wong-Law Emotional intelligence scale (WLEIS-I): A second-order factor analysis. Personality and Individual Differences, 116, 274-280.https://doi.org/10.1016/j.paid.2017.05.006

Joseph, D. L., \& Newman, D. A. (2010). Emotional intelligence: An integrative meta-analysis and cascading model. Journal of Applied Psychology, 95(1), 5478.https://doi.org/10.1037/a0017286

Judge, T. A., \& Kammeyer-Mueller, J. D. (2011). Happiness as a societal value. The Academy of Management Perspectives, 25(1), 30-41. https://doi.org/10.5465/AMP.2011.59198447.

Judge, T. A., \& Kammeyer-Mueller, J. D. (2012). General and specific measures in organizational behavior research: Considerations, examples, and recommendations for researchers. Journal of Organizational Behavior, 33(2), 161-174.

Judge, T. A., \& Klinger, R. (2008). Job satisfaction: Subjective well-being at work. In M. Eid \& R. J. Larsen (Eds.), The science of subjective well-being (pp. 393-413). New York, US: Guilford Press.

Judge, T. A., Heller, D., \& Mount, M. K. (2002). Five-factor model of personality and job satisfaction: A meta-analysis. Journal of Applied Psychology, 87(3), 530541.https://doi.org/10.1037/00219010.87.3.530

Judge, T. A., Rodell, J. B., Klinger, R. L., Simon, L. S., \& Crawford, E. R. (2013). Hierarchical representations of the five-factor model of personality in predicting job performance: Integrating three organizing frameworks with two theoretical perspectives. Journal of Applied Psychology, 98(6), 875-925.https://doi.org/10.1037/a0033901 
Judge, T. A., Thoresen, C. J., Bono, J. E. and Patton, G. K. (2001). The job satisfaction-job performance relationship: A qualitative and quantitative Review. Psychological Bulletin, 127, 376-407.https://doi.org/10.1037/0033-2909.127.3.376

Kafetsios, K., \& Zampetakis, L. A. (2008). Emotional intelligence and job satisfaction: Testing the mediatory role of positive and negative affect at work. Personality and Individual Differences, 44(3), 712-722.https://doi.org/10.1016/j.paid.2007.10.004

Law, K. S., Wong, C.-S., \& Song, L. J. (2004). The construct and criterion validity of emotional intelligence and its potential utility for management studies. Journal of Applied Psychology, 89(3), 483-496.https://doi.org/10.1037/0021-9010.89.3.483

Lievens, F., \& Chan, D. (2017). Practical intelligence, emotional intelligence, and social intelligence. In J. L. Farr \& N. T. Tippins (Eds.), Handbook of employee selection ( $2^{\text {nd }}$ ed., pp. 342-364). New York: Routledge.

Locke, E. (2005). Why emotional intelligence is an invalid concept. Journal of Organizational Behavior, 26(4), 425-431.https://doi.org/10.1002/job.318

Locke, E. A. (1976). The nature and causes of job satisfaction. In M. D. Dunnette (Ed.), Handbook of industrial and organizational psychology (Vol. 1, pp. 1297-1343). Chicago, IL:Rand McNally.

Matthews, G., Zeidner, M., \& Roberts, R. D. (2002). Emotional intelligence: Science and myth. Cambridge, MA: MIT Press.

Mayer, J. D., \& Salovey, P. (1997). What is emotional intelligence? In P. Salovey \& D. J. Sluyter (Eds.), Emotional Development and Emotional Intelligence: Educational Implications (pp. 3-34). New York, NY: Basic Books, Inc.

Miao, C., Humphrey, R. H., \& Qian, S. (2017a). Are the emotionally intelligent good citizens or counterproductive? A meta-analysis of emotional intelligence and its relationships with 
organizational citizenship behavior and counterproductive work behavior. Personality and Individual Differences, 116, 144-156.https://doi.org/10.1016/j.paid.2017.04.015

Miao, C., Humphrey, R. H., \& Qian, S. (2017b). A meta-analysis of emotional intelligence effects on job satisfaction mediated by job resources, and a test of moderators. Personality and Individual Differences, 116, 281-288.https://doi.org/10.1016/j.paid.2017.04.031

O’Boyle, E. H., Jr., Humphrey, R. H., Pollack, J. M., Hawver, T. H., \& Story, P. A. (2010). The relation between emotional intelligence and job performance: A meta-analysis. Journal of Organizational Behavior, 32(5), 788-818.https://doi.org/10.1002/job.714

Ones, D. S., \& Viswesvaran, C. (1996). Bandwidth-fidelity dilemma in personality measurement for personnel selection. Journal of Organizational Behavior, 17(6), 609626.https://doi.org/10.1002/(SICI)1099-1379(199611)17:6<609::AID JOB1828>3.0.CO;2-K

Petrides, K. V., Mikolajczak, M., Mavroveli, S., Sanchez-Ruiz, M.-J., Furnham, A., \& PérezGonzález, J.-C. (2016). Developments in trait emotional intelligence research. Emotion Review, 8(4), 335-341.https://doi.org/10.1177/1754073916650493

Ree, M. J., Earles, J. A., \& Teachout, M. S. (1994). Predicting job performance: Not much more than g. Journal of Applied Psychology, 79(4), 518-524. https://doi.org/10.1037/00219010.79 .4 .518

Riketta, M. (2008). The causal relation between job attitudes and performance: A meta-analysis of panel studies. Journal of Applied Psychology, 93(2), 472-481.https:10.1037/00219010.93 .2 .472

Sackett, P. R., Lievens, F., Van Iddekinge, C. H., \& Kuncel, N. R. (2017). Individual differences and their measurement: A review of 100 years of research. Journal of Applied Psychology, 102(3), 254-273.https://doi.org/10.1037/ap10000151 
Salgado, J. F. (2017). Personnel selection. Oxford research encyclopedia of psychology (pp. 132). New $\quad$ York: Oxford University Press. https://doi.org/10.1093/acrefore/9780190236557.013.8

Salgado, J. F., Moscoso, S., \& Berges, A. (2013). Conscientiousness, its facets, and the prediction of job performance ratings: Evidence against the narrow measures. International Journal of Selection and Assessment, 21, 7484.https://doi.org/10.1111/ijsa.12018

Salgado, J. F., Moscoso, S., Sanchez, J. I., Alonso, P., Choragwicka, B., \& Berges, A. (2015). Validity of the five-factor model and their facets: The impact of performance measure and facet residualization on the bandwidth-fidelity debate. European Journal of Work and Organizational Psychology, 24(3), 325-349.https://doi.org/10.1007/978-3-31928099-8_1280-1

Salovey, P., \& Mayer, J. D. (1990). Emotional intelligence. Imagination, Cognition and Personality, 9, 185-211.https://doi.org/10.2190/DUGG-P24E-52WK-6CDG

Saucier, G. (1994). Mini-markers: A brief version of Goldberg's unipolar Big-Five markers. Journal of Personality Assessment, 63(3), 506516.https://doi.org/10.1207/s15327752jpa6303_8

Schmid, J., \& Leiman, J. M. (1957). The development of hierarchical factor solutions. Psychometrika, 22, 53-61.https://doi.org/10.1007/BF02289209

Staw, B. M., \& Cohen-Charash, Y. (2005). The dispositional approach to job satisfaction: More than a mirage, but not yet an oasis. Journal of Organizational Behavior, 26(1), 5978.https://doi.org/10.1002/job.299

Steel, P., Schmidt, J., Bosco, F., \& Uggerslev, K. (2018). The effects of personality on job satisfaction and life satisfaction: A meta-analytic investigation accounting for 
bandwidth-fidelity and commensurability. Human Relations, 72(2), 1-31. https://doi.org/10.1177/0018726718771465.

Van Rooy, D. L., Whitman, D. S., Viswesvaran, C. (2010). Emotional intelligence: Additional questions still unanswered. Industrial \& Organizational Psychology, 3(2), 149-153. https://doi.org/10.1111/j.1754-9434.2010.01216.x.

Wong, C. S., \& Law, K. S. (2002). The effects of leader and follower emotional intelligence on performance and attitude: An exploratory study. Leadership Quarterly, 13(3), 243274.https://doi.org/10.1016/S1048-9843(02)00099-1

Yin, P., \& Fan X. (2001). Estimating $\mathrm{R}^{2}$ shrinkage in multiple regression: A comparison of different analytical methods. The Journal of Experimental Education, 69, 203-224. https://doi.org/10.1080/002209701096006 